\title{
Las funciones de Cristo, según San Agustín
}

\section{CRisto es la Verdad.}

El Concilio Vaticano II pide que se orienten los estudios filosóficos hacia el "Misterio de Cristo". Pone así sobre el tapete un viejo problema. Es fácil que cristianos y no cristianos convengan en una tesis: todo pensamiento filosófico supone ya constituída una teología, una actitud religiosa o irreligiosa previa: históricamente, la filosofía sólo puede nacer de la teología. ¿Pero podrán coincidir en una zona común, desde la cual puedan los cristianos plantear el "Misterio de Cristo"? 1 . Desde luego, no podrá tratarse de Dios (Ateísmo), ni del mundo (Naturalismo), sino quizá del hombre mismo, de lo que pudiera llamarse en términos amplios la "naturaleza humana" 2. Tendríamos que identificar al hombre actual con una natura pura, dotada de un fin propio y filosófico: conocer y amar a Dios naturalmente. Pero, de momento, esa hipótesis es imposible: Primero, porque un "estado" semejante es una ficción teológica, pedagógica, inventada para distinguir mejor lo natural de lo sobrenatural; segundo, porque el concepto es tan ambiguo que, colocado en manos del Humanismo o del Naturalismo, es un error inaceptable ${ }^{8}$; tercero, porque el hombre no cristiano ve en esa artificial natura pura una maniobra cristiana destinada a la propaganda, y no una postura de sinceridad y acercamiento; finalmente, porque el hombre de hoy, evolucionista, no quiere oir hablar de "estados" o "naturalezas" que impliquen o den pie a un fixismo anticuado.

1 J. PIEPER, Christliche Philosophie, München 1948, 503.

2 E. Berburr, Natura humana, München 1950, 19.

3. F. STEGMüLLER, Lexikon für Theologie und Kirche, IX, Freiburg 1937, 770. Diekamp ha querido mostrar que yal los Padres utilizaron este concepto de natura pura, y citia dois textos hartio clarios de San Agrustín (F. DIEKAMP, Katholische Dogmatik, II, Münster 1921, 124). Sin embarrgo, el coasol die San Agustín

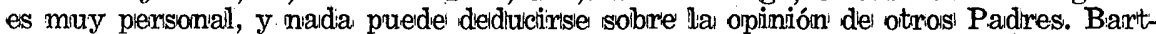
mann reconoce que las basess ise hallan wen losi Paidress, piero estitmai que ese concepto sólo en la época moldemna tiene todoi sinj carácter técnico; alsí, deberemos reconocer que comienza con ell Janisenismo (B. BaRTMANN, Lehrbuch der Dogmatik, I, Freiburg 1917, 283). Sicheeben iseñalla el Concilio de Trento como puntio de interselcción, puesto que cambió un problema histórico en un probibilema abistracto y teorético. (M. J. ScHEEBEN, Handibuch der katholischen Dogmatik, IT, Freiburg 1878, 482). Lubac ha discutido dietenidlamente este tema (H. de LuBAC, Augustinisme et Théologie moderne, Aubier 1965, 193-225; H. de LuBAC, Le Mystère du Surnatunel, Aubier 1965). 
Podría quizá hablarse de una "situación", appovechando un término moderno y una ideología moderna, ya que se supone que el hombre es la medida de todas las cosas. Pero, si utilizamos el término "situación", esta es tan variable y diferente, o mejor tan opuesta y contradictoria, en los diversos campos, que en ningún caso se puede hablar de zona común de discusión o de diálogo. Sólo le queda, pues, al cristiano contemporáneo una salida: dar testimonio del "Misterio de Cristo" ante un mundo anticristiano. A esto es a lo que nos llama Dios en la situación actual; por lo mismo, en este sentido tendremos que interpretar las palabras del Concilio Vaticano II.

El mensaje cristiano podría enunciarse en estos términos: Dios quiere que todos los hombres se salven y con esa finalidad ha ofrecido y entregado al Mundo a su propio Hijo. Creó a los hombres para que alcancen la salud o salvación "en" y "por" su Hijo y participen de la naturaleza divina. Tal es el alegre mensaje, que siempre se ha designado con el nombre de Evangelio: abrir los corazones a la esperanza. Pero este fin, que los cristianos predicamos al Mundo, no puede alcanzarse ni por la Ley Mosaica, ni por la Filosofía, sino tan sólo por la gracia de Cristo. Y éste es el "Misterio de Cristo".

Se vienen haciendo ensayos para aplicar la orientación del Concilio, y todos debemos cooperar en una tan importante empresa apostólica. En el presente trabajo vamos a analizar el problema en un caso histórico, pero radical y fundamental: no sólo vale para una discusión teórica del problema, sino que equivale a una discusión teorética y abstracta, y aún tiene algunas ventajas sobre la discusión especulativa. Vamos, pues, a estudiar el caso típico de San Agustín. El fue quien obligó al Clasicismo a ponerse de acuerdo con el Catolicismo, mientras obligó al Catolicismo a ponerse de acuerdo con el Clasicismo. Se vio, pues, obligado a estudiar la relación entre Filosofía y Teología, razón y revelación, evidencia y autoridad. Pero se trata sólo de sentar unas bases: el tema es tan amplio que daría lugar a muchos libros, con sólo reunir los textos agustinianos. Trataremos, pues, tan sólo de hacer ver cómo nacieron en él las teorías, dejando para otros la labor de continuar cada uno de los muchos temas que iremos levantando. Será, pues, este un estudio sobre principios y fundamentos.

Vamos a distinguir en San Agustín tres posturas diferentes: inicial, media y final. Hoy es imposible olvidar la evolución, que fue cambiando la ideología de San Agustín: correríamos el riesgo de resultar "falaces" al dar a los textos agustinianos un sentido que no tienen en su determinado tiempo. Acentuamos así el carácter evolutivo de la doctrina, y ponemos de relieve el sentido del problema total. De este modo, nuestro estudio tendrá valor actual: antes de trazar un camino hacia adelante, es necesario mirar atrás.

En la época de su escepticismo ${ }^{4}$ se preocupó Agustín por el problemande

4 Confess. VI, 10, 19, PL. 32, 715. 
la "autoridad", que estaba ya planteado en Cicerón ${ }^{5}$. Sus meditaciones le condujeron hacia una dialéctica, que podríamos expresar con un texto bíblico: Yo soy el Camino, la Verdad y la Vida (Jo. 14,6). Siempre que se trate del Verbo o de Cristo, será preciso suponer esta dialéctica.

La primera preocupación de Agustín fue la fe, Cristo-Camino, ya que la fe es necesaria incluso para vivir ${ }^{6}$. Admitido ya el Camino, Agustín se inscribió en la lista de catecúmenos, como en su infancia ${ }^{7}$. Su fe se refería entonces a la

5 A te enim philosopho rationem accipere debeo religionis, maioribus nostris etiam nulla reddita ratione credere (Cicerón, De natura Deorum, III, 2, 6). Quod mihi persuassum est auctoritate maiorum, cur ita sit nihil tu me doces. (Ibid.).

Durante este período explicaba Agustín a sus alumnos ide Retórica la filosiofía de Cicerón, diisicutía con suisı amilgois Allipito y Nebriidio el pirobilema del último fin y dell último bien, y padecía homdlas congojjas meligiosas y piensonales".

6 EI argiumentol dè "autoriidad" está orientaido contral ell maniqueismo y contra el iparganismo; al mismo tiempo que icontral Porfiriio (Confess. VI, 4, 5, PL. 32 , 721). Eistia fe esi die momento una fe humana, aunique excepcionalmiente garantizaidia (Confess. VI, 5, 7, PL. 32, 722). Credere coeperam nullo modo Te fuisse tributurum tan excellentem illi Scripturaie per omnes jam auctoritatem, nisi et per ipsam Tibi quaeri voluisses... Ut exciperete omnes populari sinu, et per angustai foramina paucos ad Te traiiclerlet. (Ibŕd. VI, 5, 8, PL. 32, 723). Dos teorías pressentai aaquí Agustín: un plan des salvación, orgtanizaido por la divina: Providlencia, y una contrapositción die la via lata o poipular de la fe a la via arcta o fillosófica del entendimiento. Porr veso, diviide Agustín la "auttioridad" en "divina" y "humana". La idivina corresplonide 'a la auctoritas' maiorum, die Cicerón, pero ahora con todas las garantías, puesto que Crristo most of mece su autorridald divina en una forma histiórica y millagrosia: tall era, all parecer, ell argumento die Sirmpliciano, cuandoo habló a Agtustín del la converssión de Victorino. En este sentrido han de intierpretarse algunos textos idudossos ide Agrusitín: cui (Philosophiae Intelligibili) animas multiformibus erroris tenebris caucatas et altissimis a corpore s.ordibus oblitals, nunquam istai ratio subtiilissibma rlowockaret, nisi summus Denis populari quadam clementia divini intellectus auctoritatem usque ad ipsum corpus humanum declinarrett aitque submiteret (C. Ackad. III, 19, 42, PL. 32, 956).

Auctoritas anitem partim divina est, partim humana: sedi vera, firma, sum mague est ea quae divina nominatur (contra Cicerón). In qua metuenda est aeriorum animalium mira fallacia (contra la teurgia ide Porfirio).... Illa ergo augtomitas divina didenda est," quaje non solum in slensibilibus sigmis tratcendit ommem humainam facultaitlem, sied et ipsum hominemi aignemis, ostendit en quousque se propter ipsum depreserit (kenosis).... Qwoe omnia sacris, quibus innitiamur, secretius firmiusque traduntur: in quibus bonorum vita facillime, non disputationum ambagibus, sed muysteriorum auctoritate purgatur... (De Ordine, II, 9 , 27, PL. 32, 1007 ssi.). Estais interesantes declaraciones demuestran muchas cosas. En primer lugar, demuesstran que el círicullo criststiáno y platónico des Milián utilizaiba el mortivo ide la Encarnación dientro diel platomismo; demuestitran, en se gundio lugar, que Agusitín conisildelra el Clatolliciismo como un "misterio" en el que hay que "iniciarise": no blasstai idecir que había una disciplinta dell arrcano, sino que es necessario apuntar, quie el conciepto de "misterrio" y de "iniciaido" no son justois ni exactos, cuanido isle trata idiel Catollicismol, que mo els una filloisoffía parra isellectos; idemuesttran, en tericer; luggar, que Aggustín tenía medios para desarrollar estoss pensiamientos, si. huibiera' tenido interés, Quería "entender", no "creer". Por todo esto me parece un tanto ingenua la interprietación del P. Bavel (T. J. van BAvEI, Recherches sur la Christologie de S. Augustin, Fribourg 1954,6$)$.

7 Confess, V, 14, 25, PI. 32, 718. 
Biblia y solo indirectamente a la Iglesia o a Cristo. Esto significa que le urgían aún el escepticismo y el problema de los criterios.

Pero la influencia platónica hizo que se preocupara del Verbo-Verdad más que del Verbo-Camino. Daba por supuesta y natural la fe, pero quería a toda costa "entender" y el platonismo le llevaba a buscar la verdad iluminante y absoluta. La teoría maniquea del Antropos y la neoplatónica del Nous le ayudaban, y él creyó todo solucionado de momento, al identificar el Logos helénico con el Logos de San Juan ${ }^{8}$. Según el mito maniqueo, se trata de un dogma religioso: el Antropos nos ilumina (gnosis), despertando en nosotros la consciencia de nuestro origen divino, y proponiéndonos unas normas teóricas y prácticas para regresar a El. En el platonismo, la Filosofía es una gnosis, o iluminación, que nos hace recobrar también la consciencia del origen divino, dándonos normas pata regresar a la "región lejana" o Patria ${ }^{9}$. No es un dogma, sino una teoría.

Quedan de momento identificadas la Religión Católica y la Religión Natural. Fe e inteligencia son dos formas de la misma iluminación o gnosis. Cuando después de haber leído a los platónicos, lee Agustín a San Pablo, nada le sorprende: halla que coincide con ellos en todo, añadiendo tan sólo por su parte una recomendación de la gracia divina ${ }^{10}$. Pero no pensemos que esta fórmula es teológica o dogmática: gracia divina significa simplemente el acceso a Dios que ofrece la Filosofía. Es, pues, una gracia natural. Agustín parece referirse a la Epístola a los Romanos, concretamente al texto Rom. 1, 20. Por lo menos, lo cita tres veces seguidas en ese pasaje ${ }^{11}$ y en otros semejantes utiliza el término "gracia" en ese mismo sentido amplio ${ }^{12}$.

Según lo dicho, los primeros textos que Agustín nos ofrece sobre Cristo, no parecen referirse a una Cristología propiamente dicha, sino más bien a la autoridad divina, esto es, a los motivos de credibilidad, que garantizan la fe y la hacen "razonable".

Diremos entonces que Agustín se halla situado entre Cicerón y Porfirio. Por un lado, según Cicerón, sólo la autoridad puede afrontar el problema de la salvación, ya que la filosofía ni enseña ni demuestra nada ${ }^{13}$. Por el lado contrario,

8 Confess. VII, 9, 13, PL. 32, 740. 1.190).

9 In lumine, scilicet in Christo accipiendum (De Musical, VI, 16, 51, PL. 32,

10 Confess. VII, 21, 27, PL. 32, 747.

11 Confess. VII, 9, 15, PL. 32, 741 y 742.

12 Videtis utcumque, etsi de longinquo, etsi acie caligante, patriam in qua mamendum est, sied viam qual eundum est nom tienietis , Confitieris! tamien oratialm, quandoquidem ad Deum per virtutem intelligentiae pervenire, paucis dicis esse concessum (De Civ. Dlei. X, 29, PL. 41, 307 y 312). J. J. O'Mrara, "A Master Motiv in Sit. Auguistine". Actes du Prémier Congrès de la Fédération International dies Associations d'Ethudes Clasiques, Paris 1951, 312. J. J. O'Meara, The Young' Augustine, Londion 1954, 143 iss.

13 Cfr. Notia 5. 
según Ponfirio, sólo la Filosofía es la via arcta de la salvación, ya que el problema de la autoridad no tiene solución: la tendría, si existiese una personalidad o una escuela con suficiente autoridad para ofrecer a los pueblos esa via lata, que es la fe; pero tal personalidad o tal escuela no existe. Agustín da aquí la réplica a los dos, al romano y al griego: existe esa personalidad o esa escuela, dotadas de autoridad para garantizar la fe popular, sin que se convierta en "viciosa credulidad" : la personalidad es Cristo, y la fe es el Cristianismo ${ }^{14}$. En cuanto a Cicerón, Cotta cometía el error de creer que el éxito de las armas romanas se debía a su religión, y que el éxito de su religión se debía a la vendad de esa misma religión. Agustín no tiene necesidad de detenerse a combatir el paganismo, que para él es una postura ridícula, y se contenta con aprovechar las ideas de Cicerón para su fin propio.

Cristo significa, pues, para Agustín ante todo un "Camino", pero ese Camino se va a reducir a la Verdad. Según el testimonio de las Confesiones Agustín no creía aún en la divinidad del Cristo histórico, y por lo mismo esa "autoridad" era la de un hombre, aunque fuese el mayor de todos los sabios. Por eso la autoridad de magisterio, propia de Cristo, y la autoridad o garantía que podía proporcionar la iluminación de un Logos, iban por separado todavía. Es verdad que la lectura de San Pablo debió ayudarle a formarse un concepto más amplio y exacto de la naturaleza de Cristo, pero el hecho de no explicarnos nada a este propósito, y de exponernos luego sus cambios de mentalidad, indica que sus ideas sobre Cristo eran todavía demasiado imperfectas o falsas. Esto no era nada extraño, dados sus antecedentes maniqueos, estoicos y neoplatónicos.

Quien debió hacenle comprender el auténtico carácter de la autoridad de Cristo fue Simpliciano ${ }^{15}$. La conversión al Cristianismo se realizó ya bajo el mis-

14 C. Acad. III, 20, 43, P.L. 32, 957. Vemos, pues, ccon todla claridad que el mottivo ide Crisito-Camino ess anterior o contempooráneo al mortivo Cristo-Verdiad. El que luego Aggustín idessarrollasie tanito el tema del Maesitro Intierior, mientras drejlaba prácticamente sin comentario el tema del Maestro exterior y Modelo, es lo que le pesará más tarde como una culpa, al irsse desspegando del esspáritux platónico piara introlducirsse en el espínitu de la Biblia. Eisiai "confesión" sigmífica una renuncia la la identificiación icon el Platonịsmo y a lasi "zonas comuneis" con los filósofos. En adelante, Agusítín dará testimonio de Cristianismo ante el mundio, y combatirá a todors los quie lle combratan a él. Sobre la relación entre los títrulos que Agrustín da a Criisto y las funcriones que le lasigna, Cfr. J. MoHAN, De Nominibus Christi, doctrinam divi Augustini christologicam et soteriologicam exponentibus, Mundelein-Illinois' (U. S. A.) 1937, 1 isIs. y 44-49.

Tantam auctoritbutêm maigisterihi meruilssie vidiebattur. Quid autem siacramiemti haberet Verbum carro factum est, ne suspictari quidem poteram. (Confiess. VII, $19,25, \mathrm{PL} .32,746)$.

15 Afirma que ya le gustabia entioncesi "ell camina diel Stalvadior", aunque le daba miedo su austeridad, y que por eso fue a consultar a Simpliciano. (Confess. VIII, 1, 1, PL. 32, 749). Sin embarmo, en losł Dilálogos de Casiciacer sel habla de masilardo pooco de Clristo como camino. Más bien se refiere a la Veridad. Piero ess cierto que Simplliciano le hizo ver ell cartácter det Camino die Criisto: "Deinde, ut me exhortaretur ad humillitatem Christi... Viatorinum igsum recondatus est. 
mo signo de la conversión de Victorino: doblar el cuello al yugo de Cristo. Pero con eso, los dogmas se convierten en principios filosóficos y los principios se convierten en dogmas. La fuente común es la iluminación del Verbo ${ }^{16}$.

Agustín era entonces un filósofo. Como teólogo, estaba mal informado sobre dogmas tan fundamentales como la Trinidad Personal ${ }^{17}$ y la divinidad de Cristo ${ }^{18}$. Esperaba en la mística del mundo inteligible ${ }^{19}$, dedicaba sus ditirambos a la Filosofía ${ }^{20}$, y se presentaba como platónico dispuesto a rendir vasallaje a Cristo ${ }^{21}$.

Su concepto de la fe era insuficiente y aún falso. La fe, según él, es necesaria, pero sólo en cuanto que la inteligencia demanda sus servicios provisionales. Es el extremo opuesto a un San Anselmo, para el cual la misma Filosofía es Fides quaerens intellectum. Agustín quiere ser sabio o "espiritual", no párvulo o "carnal". Su preocupación es "entender" los dogmas, obligar a la fe a arrancarse la venda tradicional y a "ver". La misma $f e$ es un procedimiento racional, un intellectus quaerens fidem ${ }^{22}$.

Se dirá que con frecuencia adopta una postura contraria ${ }^{23}$. ¿Creeremos entonces en esa frívola solución de las "indeterminaciones", que serían contradicciones? De ningún modo. Entonces, nos interesa entrar en su pensamiento. Para él, la filosofía ha llegado a la alternativa final : o escepticismo o platonismo. El llegó con ella hasta el escepticismo y salió de él con ella para adoptar el platonismo. ¿Pero qué ha de entenderse por platonismo?

Platonismo significa: negativamente, desahucio de toda filosofía que pretenda contentarse con relativismos y elementos de este mundo; es necesario llegar a un absoluto y necesario; positivamente, significa recurso a Dios como principio y fundamento del mundo noético, físico y moral ${ }^{24}$. Y puesto que, al

(Confess. VIII, 2, 3, PL. 32, 750. De Civ. Dei, X, 32, 3, PL. 41, 315). P. CourCEILL, Recherches sur les Confessions diel S. Augustin, Partis 1950, 168 iss.; J. J. O'MEARA, "Neoplatonism in the Conversion of St. Augustin": Dominican Studies (1950) 343 .

16 G. NYGREN, Das Prädestinationsproblem in der Theologie Augustine, Göttingen 1956, 140-176.

$17-$ Ep. 11, 3, PL. 33, 76 s.

18 Confess. VII, 19, 35, PL. 32, 746.

19 Solil. I, 6, 12, PL. 32, 875.

20 De Ordine I, 11,31 s., PL. 32,993 s.; C. Acad. III, 20-43, PL. 32, 957 ;

E. IVANKa, Plato christianus, Einisiedeln 1964, 189.

21 K. BARTH, La Preuvie de l'Existençe diel Dieú d'anrés Ansielm del Cantorbery, Paris 1958, 19 s.

22 Ep. 120, 3 s., PL. 33, 433; De Agone christiano 33, 34, PL. 40, 309 s.;

De Trinit. I, 1, 2 s., PL. 42, 821 ; XIII, 19, 24, PL. 42, 1.033.

23 Retrac. Prólogo, PL. 32, 583 s.; C. A cadd. III, 20-43, PL. 32, 957; De

Vera Relig. 3, 3, PL. 34, 123; J. RITTER, Mundus intelligibilis, Frankfurt 1937, 39 ss.

24 De Vera Relig. 3, 3, PL. 34, 124.

"Plato a Ciclerone mutivis modis osidemditun", in samijientia noin humama, sibd plane divina... constituisse elt finem boni (Etica), et causas rerum (Ontologia), 
decir Dios, Agustín entiende el Dios personal y trascendente de los judíos y cristianos, le queda despejado el camino para su revolución genial: ni su teología natural, ni su religión natural, ni su ley natural, ni su derecho natural, son conceptos griegos, sino conceptos cristianos.

La inteligencia humana es radicalmente una participación en el Verbo. La evidencia brota de una iluminación natural y es para el hombre un yugo, lo mismo que la fe. Dios intima su voluntad por medio de la fe o por medio de la inteligencia, y tanto vale una revelación natural como una revelación positiva. Puede hablarse contra la inteligencia o contra la fe, pero sólo cuando se supone que no son rectas, porque, si son rectas, están garantizadas por el Verbo. "Entender" es una actividad religiosa, si se practica conscientemente, es una subjunctio, una subordinación a la luz divina. Si hay una impiedad, que consiste en sacudir el yugo de la fe, hay otra impiedad, que consiste en sacudir el yugo de la inteligencia. La Filosofía y la Teología pueden mutuamente condicionarse, sin incurrir en círculo vicioso, puesto que ambas vienen de la misma fuente, que es el Verbo ${ }^{25}$.

Así, es imposible concebir que Agustín atente contra la Naturaleza, si nos atenemos al concepto propio de la misma. $Y$ no ya sólo durante la época antimaniquea, en la que Agustín hubo de defender la bondad de toda naturaleza criada por Dios, sino también durante la polémica pelagiana: es imposible concebir, nos dice, que Dios cree las naturalezas de manera, que luego les quite las leyes que les dio, según la condición de cada una. Por lo mismo, las relaciones entre Filosofía y Teología habrán de ser cordiales y sinceras. En cuanto a la doctrina concreta, Agustín da por supuesta la dialéctica de las tres hipóstasis neoplatónicas. Pero aquí realiza la misma hábil operación, convirtiendo la trinidad platónica en la Trinidad personal y trascendente de los cristianos. Hallamos tres esferas en la metafísica, una ontología trinitaria, en; la que el Verbo asume la función reveladora ${ }^{26}$.

Las consecuencias no se hacen esperar. Agustín comienza por atribuir a los platónicos el concepto de creación cristiana, que es un concepto bíblico y teológico. Así cambia automáticamente el sentido del término "principio". Los principios griegos suponían siempre la inmanencia: ahora el "principio" creacional es personal, trascendente, es el Pádre. Se plantea ante todo el problema existencial, según el cual los seres son llamados a la existencia y se convierten en "criaturas". El Cristianismo afirmaba la creación como un dogma. Al afirmarlo ahora Agustín como principio filosófico, el "ser" se convierte en un valor, aunque in-

et ratiocinandi fidutiam (Noética) (Ep. 118, 3, 20, PL. 33, 441; De Civ. Dei VIII, 5-11, PL. 41, 229-235).

25 "Ut perspicuae rationi ommis humana intelligentia subirugetur... ( $\mathrm{De} l i$ bero Arbitrio III, 21, 60, PL. 32, 1.300).

26 Confess. VIII, 9, 13, PL. 32, 740 s. 
dependiente e irreductible (Ontología). Solo consecuentemente se plantearán el problema esencial y el problema natural ${ }^{27}$.

La misma operación practica Agustín en el segundo miembro de la dialéctica metafísica, al afirmar que los platónicos defienden la teoría del Verbo cristiano Hijo de Dios, identificando con El el mundo inteligible, que de ese modo se convierte en un plan divino, en un ejemplarismo y en una formación, puesto que el Verbo cristiano es la Sabiduría de Dios y la Virtud de Dios ${ }^{28}$. La iluminación o formación, consecutiva a la creación, es ya otro principio trascendente, un valor: la esencia de cada ser es el término de una libertad y no de una necesidad. Dios no es un Zeus, sujeto a la Anánke. Cada ser es lo que Dios quiere que sea, una semejanza del modelo divino, según su género y especie. Nada hay fijo en la forma, que es semilla, razón seminal, dotada de números espaciales y temporales dentro de un plan de Dios y: de una Ley eterna ${ }^{29}$.

Asimismo, también en el problema del orden u ordenación practica Agustín la misma habilidad. El cosmos no salió a se y per se del caos, en virtud de una forzosidad, ananke, dike, sino de una voluntad creadora: por ende, también la naturaleza es un valor, es el estatuto ontológico, que Dios ha otorgado a cada criatura, como pacto, alianza, ley, fuero o código. $Y$ así el término natura lo abarca todo: puede significar ser, esencia, orden-ley, reino físico en oposición al espíritu, etc. ${ }^{30}$.

De este modo, Agustín ha llevado y orientado los estudios filosóficos hacia el "misterio de Cristo" de un modo tan radical que la verdadera Filosofía y la verdadera Religión se identifican con el Cristianismo. Pero lo ha logrado, por decirlo así, bautizando en secreto al Clasicismo. Esa Filosofía griega, que comenzó siendo una Cosmología, fracasó al verse obligada a convertirse en Criteriología. Agustín la sacó del callejón sin salida, pero imponiéndole condiciones: la filosofía no es un repertorio de tesis rígidas, como la Naturaleza no es una jerarquía de sustancias rígidas. El Universo no es un eterno retorno, una eterna candonga sin sentido ninguno: es una evolución, una creación continua. No se puede, viene a decir Agustín, atentar a la independencia irreductible de la Filosofía,

27. Agusitín adviente que el verbo "ser" tiene ya differente significiado en la Biblia y en Grecia: et inspexi caetera infra $T e$, et vidi nec omnino esse, nec omnino non esse... (Confess. VII, 11, 17, PL. 32, 742.)

28 Die div. Quaest. 46, 2, PL. 40, 30; De lib. arb. II, 11, 30, PL. 32, 1.258. En estos clasols suele citar el texto Sap. 8, 1: attinrit a fine usque ad finem fortitier, eit disponit omnia suavitier, tomando la virtus y la sapientia como funciones ejecuitiva y ejemplar, atriburildas tradicionalmente all Verbo.

29; A. MITTERER, Die EntwicklungsLehre Augustins, Wien-Freiburg 1956, 30-32. De lib. arb. II, 17, 45, PIL. 32, 1.265. De ester modo dla forma ess, como el ser, una "gracia”, una donación (De Gen. ad litt. imp. liber 16, 54-62, PL. 34, 241- . 244; De Vera Relig. 36, 66, PL. 34, 151 s).

30. De Ordine. II, 17, 46, PL. 32, 1.1016; De Vera Relig. 39, 72, PL. 34, 154. A vecess vacilla, disstinguiendo la tricotomía cuempo-alma-espiritu, entendiendo por espíiritu la mens. 
pero la Filosofía no está sola en el mundo; es mensajera de Dios pero propter bomines. La Encarnación ha sido una revelación y su noticia tiene que ser registrada en todos los ángulos del globo.

El propter bomines hace ver a Agustín que, siempre que cambie el concepto de natura bumana o de "situación humana", tiene que cambiar radicalmente la Filosofía. Si Agustín llega a concluir que, independientemente de la "evolución", como hoy decimos, la situación del hombre depende de un pasado, de una historia, de un acontecimiento lamentable, que llamamos pecado original, pecado que automáticamente es una nelación a la Encarnación del Verbo, a Cristo, habrá que conceder que esa zona espiritual del hombre, que llamamos espíritu, o Memoria Dei, no es una zona sometida a la evolución y orientada al futuro, sino un resto glorioso de una raza venida a menos, una cabeza de puente, que el Verbo se ha reservado para iniciar una reconquista.

La función reveladora del Verbo, que Orígenes había detenidamente explicado contra Celso ${ }^{31}$, cobra en Agustín un sentido nuevo, ya que es nueva su teoría de la iluminación. En primer lugar, la teoría de la iluminación pone en contacto con el Verbo a todo hombre que viene a este mundo, ya que El es la luz de todo hombre que viene a este mundo (Jo. 1, 9), y esto tiene, según Agustín, un sentido filosófico; en segundo lugar, porque la iluminación filosófica, constituye a la memoria en "sindéresis universal": no se refiere sólo a las verdades especulativas, sino también a las religiosas y morales, que disponen y catartizan a la razón especulativa. Nadie, dice Agustín, se hace justo con la justicia de otro, sino con la propia; y la propia se logra adaptando el alma a las regulae vel lumina virtutum ${ }^{32}$, que constituyen nuestra unión noética y metafísica con el Verbo. El Logos es un lazo de unión entre Dios y las criaturas, no sólo como causa eficiente y ejemplar, sino también como causa reveladora. El espíritu humano está hecho de modo que "naturalmente" está en el Verbo como el ojo está en la luz ${ }^{33}$. Y por eso Cristo es ante todo la Verdad, el Maestro interior, y el espíritu humano ha sido creado a sú imagen, pero además ejus capax eique congruens, según el texto ya citado.

De donde podemos deducir que la Memoria Dei, la potencia obediencial, no es pasiva, aunque tampoco es úna potencia griega, capaz de pasar al acto por

31 T. KerM, Clelsus'Wahres Wort, Zürich 1873, 275, 278; M. HARL, Origène et la fonction du Verbe incarné, París 1958, 2 sis.

32 De lib. arb. II, 19, 52, PL. 1.268; De b. vita 4, 34, PL. 32, 975; De Ordine II, 19, 51, PL. 32, 1.019; De Mor. Eccl. I, 13, 22, PL. 32, 1.320.

33 Más tardé concluirrá Aguistín su frase célebrre: credendum est mentis intellectualis ita conditam lesse naturam, ut rebus intelligibilibus naturali ordine, disponente Creatore, subiuncta sic ista videat, quemadmodum oculus carnis videt quale in hac inclorporiea luce circumiacient, ciuius lucis clapiax eique congriems est creatus. (De Trinit. XII, 15, 24, PL. 42, 1.011; De Magistro 11, 38 ss., PL. $32,1.216$ s.) 
sí misma. ¿Qué es entonces? Un memorial, una ruina, un monumento, una situación miserable que "clama al Cielo". ¿Acaso no tiene fuerza la miseria para mover a compasión Esa Memoria Dei, que es una diminutio ${ }^{34}$, es un abismo elocuente: abyssus abyssum invocat. Exhibimos, nuestra miseria, hacemos una demostración, un desfile de inválidos, pero no reclamamos, ni exigimos, ni protestamos.

La Filosofía enmudece, al ver que le profundizamos y complicamos sus problemas lógicos: se ve compelida a confesar sus limitaciones, ya en plan de reserva, ya en plan de sincera confesión. Tiene que confesar que recibe la luz de lo alto, $y$, si no tiene mala fe, habrá de adoptar una salida noble: ir cayendo insensiblemente en los brazos de la Teología, que es su hermana, no su rival ${ }^{85}$, Es verdad que hoy, aún dentro de la teología católica, cuesta trabajo relacionar a la Filosofía con Cristo. Pero la culpa es nuestra: hemos andado en malas compañías y los griegos nos han seducido; hemos cedido demasiado con anterioridad. Por otra parte, el Protestantismo, el Bayanismo, el Jansenismo y el Modernismo nos han obligado a pelear tanto, que en todas partes vemos enemigos. Por eso nuestra Naturaleza y nuestra Sobrenaturaleza se miran con recelo y extrañeza ${ }^{36}$. Nos cuesta hacernos cargo de que fuimos creados "en" y "por" Cristo y de que la creación no es un Naturalismo, al que haya que añadir más tarde un Sobrenaturalismo, como un remiendo nuevo en un vestido viejo ${ }^{37}$. ¿Por qué habíamos de llevar nuestras distinciones hasta un punto, en el que damos la impresión de que Cristo vino a buscar una oveja perdida, que no era suya? Su de-

34 Quia rationalis creatura Verbo illo tanquam optimo cibo sui pascitur; humana autem animal ratiomalis est, quae mortalibus vinculis peccati poena tenebatur, ad hoc diminutionis "Medlacta, ut pier clondeaturas nerum visibrilum ad intelligendia invisibilia niteretur... (De lib. arb. III, 10, 30, PL. 32, 1.280). A esita comida del espíritu, que es el Vierbo se refería en las Confessiones: cibus sum grandium (Confess. VII, 10, 16, PL. 32, 742).

35 De div. Quarest. 9, 23, PL. 40, 16.

Anima aeternitatem vel intelligitur vel creditur consequi, sed aeterna aeternitatis participatione fit. Eit ildeo nihil sit Deo coniunctius (De div. Quaest., PL. 40, 33). Nulla interposita substantia ab igsa Veritate formatur... Haeret enim Veritate nulla interposita creatura (Ibíd.).

36. Los nombires de Carlos Eischweiler, Romano Guardini, Gottlieb, Söhngen y Miguel Sichmaus en la dirrección tomista, y las nombres de Erich Przywara, Karl Rahner y Hans Uris von Balthasar en la dirección molinista y juntamenie el movimientol de renovación de la teología protlestante, iniciado por Karl Barth, están diemostrando que debemos preocuparnos de penetrar en las íntimas reliaciones de la naturalieza y de la gracia, más bien que de diflerenciarlas para defendermos los unos de los otross. Criisto no vino a una casa extraña, sino a la suya propia: in propria venit: (Jo, 1, 11). U. KüHNG, Natur und Gnadle. Untersuchungen zur dieustchen katholischen Theologie der Gegenwart, Berlín 1961;H. KüHNG, Rechtfertigung. Die Lehre K. Barths und eine Katholische Besinnung. Einsiedeln 1957. Bien conocido es el nombre del P. Lubac y suls últimas publicaciones.

${ }_{37}$ K. EschWEILE, Die zwei Wege der neueren Theologie, Augsburg 1926 , 188; U. KüHNG, Natur und Gnadle, Berlín -961, 12 ss. 
recho de propiedad era radical : no era un título jurídico, sino la misma creación y formación. Cristo vino a reformar lo que $\mathrm{El}$ mismo formó, lo que era suyo. Quizá esa Memoria Dei, que nosotros tratamos de considerar como un oscuro monolito, sea en realidad un pedestal: el pedestal de una estatua que se ha caído.

Cristo es también la verdad en cuanto Verbo Encarnado. Si la Encarnación fue por sí misma una revelación de los misterios de Dios, fue luego el principio de las revelaciones concretas que nos hizo Cristo, el Verbo Encarnado. Sus Evangelios, sus doctrinas, dieron las bases a nuestra Teología y aún a nuestra Filosofía. "¿Señor, a quién iremos? Tú tienes palabras de vida eterna" (Jo. 6, 69). No seguiremos, sin embargo, este tema. Primero, porque los Tractatus in Johannem, de Agustín, nos dan un tratado completo e inmenso; y segundo, porque, hasta cierto punto, este Cristo, que es la Verdad para conducinos al Cielo, es por eso mismo el Camino. Por lo cual tocaremos ese punto en el segundo apartado. Unicamente recordaremos, antes de dejar este tema, que la Encarnación era el mentís más completo a los sistemas imperantes en el mundo, aunque Agustín no se dio cuenta de ello al principio. La mejor refutación del maniqueismo, del platonismo, de todos los dualismos que condenaban el cuerpo, la carne, lo sensible, lo temporal, era decir: el Verbo se hizo carne. La mejor revalorización de la materia, del cuerpo, de la carne, de la vida sensible y transitoria, era decir con sencillez: el Verbo se hizo carne. ¿Es que el mundo no necesitaba y necesita aún esa lección fundamental? Por eso, no sólo la divina Persona,-- sino también la naturaleza humana de Cristo es para este mundo la Vendad.

\section{Cristo es el Camino.}

Aunque Agustín no se detuvo bastante en esta fórmula durante su primera época, la fórmula no dejó de influir poderosamente en su ideología. Simpliciano le narró la conversión de Victorino para que cobrara conciencia de que aceptar el Cristianismo significaba aceptar el yugo de la humildad. Mas, como Agustín se preocupaba entonces sobre todo de superar el escepticismo y el maniqueismo, prefería insistir en la función del Verbo como Verdad. De paso recuerda, sin embargo, Agustín que el Verbo se hizo carne para libertarnos ${ }^{38}$. Se trata ahora del Verbo Encarnado, de Cristo en cuanto tal, y ês imposible negar que ese concepto ejerció una profunda influencia en Agustín desde su conversión y gracias a Simpliciano ${ }^{39}$. Necesitaba una "autoridad suficiente" para creer y la encon-

38 Vult autem intelligi, Adam qui peccavit, veterem hominem; illum autem quem suscepit in sacramento Dei Filius ad nos liberandos, novum (Die Mor. Eccl. I, 19, PL. 32, 1.326).

39 O'Meara y Courcelle, en los libros ya citados, han insisistido en este punto. Cf'r. Nota 6. 
tró en Cristo: ese era, pues, para él el primer motivo de la Encarnación. De este modo, Cristo es para Agustín un Camino, el Camino que nos lleva a la Verdad.

Esta fórmula podría entenderse de diversos modos. Camino significa ante todo un método y en este sentido es claro que el método de Cristo significa ir a la inteligencia por medio de la fe: crede ut intelligas. Pero significa también aquella preparación moral que Agustín pedirá siempre ${ }^{40}$. Es, pues, una catarsis acomodada al Cristianismo. Así puede ya Agustín afirmar contra Porfirio que está garantizado el camino universal de salvación, que es la fe en Cristo, puesto que Cristo ha merecido esa fe.

Agustín se incorpora así a la tradición eclesiástica, bien representada por San Ambrosio. Pero también aquí es Agustín original, gracias a sus antecedentes maniqueos. El Antropos no se contenta con la gnosis elemental de despertar las conciencias, sino que revela al hombre una vida moral que concretamente se . cifra en los tres sellos. Y no hay que olvidar que Agustín, al convertirse, abrazó el monacato, entregándose así a la via Salvatoris: placebat via, ipse Salvator, et ire per ejus angustias adbuc pigebat, como dicen las Confesiones. Aquí comienza una teología del monacato que los cristianos actuales tendrán que repasar, si es verdad esa sinceridad que tanto se cacarea.

Cristo vino, pues, a reforzar su iluminación filosófica, dándonos un cúmulo de doctrinas concretas y vivificantes, y al mismo tiempo dándonos ejemplo de vida. En este sentido, ya que El fue nuestro modelo en la creación, habrá de ser nuestro modelo también en la "recreación" o reformación. El ejemplarismo se extiende a la vida religiosa del género humano. La predicación de Cristo nos llevará ante todo a las tres virtudes teologales y fundamentales ${ }^{41}$. El cristianismo había sido designado en su primer período como un "Camino" y en la antigüedad ese era el término para designar una postura, una actitud, un género de vida y aún de pensamiento, un estilo.

Agustín hubo de reaccionar vigorosamente contra los maniqueos, convirtiendo el "camino cristiano" en una apología contra el "camino maniqueo", en un libro titulado Sobre las costumbres de la Iglesia Católica y de los Maniqueos. Nos remitimos a él. Piensa Agustín que es necesario averiguar cuál es el último fin o último bien del hombre, ya que la bienaventuranza consistirá en "amar y poseer" ese último bien final. "Amar y poseer" equivale a contemplar, a ver con amor (Frui). Y como se supone que el alma humana comienza por estar vivien-

40 De Ordine H, 8, 25, PL. 32, 1.006. No se itrata en estos clasios de anteponer la Eltica a la Noéticia o a la Ontología. Son cossas differentess. Siel trata de currar a la razón de sulss apegos, piarra que sea "limplia y recta" (Solil. I, 6, 12 s., PL. 32, 875 s.). Aquí se reúnen, pues, las doss funciones, Verdad y, Camino. Cffr. Nota 33.

41 Die lib. arb. II, 20, 54, PL. 32, 1.270. 
do una vida que hoy llamaríamos "inauténtica", sólo puede cobrar autenticidad siguiendo a alguien. No puede el alma seguirse a sí misma, puesto que se seguiría aquella sentencia famosa: el que es maestro de sí mismo, es discípulo de un loco. Sólo queda seguir a alguien. ¿A quién? Los hombres fallan: son contingentes y aún evanescentes, y nos abandonan en el mejor momento. Tenemos, pues, que seguir a Dios. Seguir a Dios es la Filosofía, conseguir a Dios es la bienaventuranza. Y como no vemos a Dios, para seguirle, sólo tenemos ante nosotros el camino de la probabilidad y el camino de la fe. Este es el camino cristiano. La Filosofía tiene que confesar que es impotente para resolver un problema semejante, ya que está incapacitada para contemplar las cosas "divinas". Tiene, pues, que mirar a la Fe con el respeto que se debe a quien nos saca de un aprieto. Ese camino, que se nos presenta ahora como "moralidad", no es otra cosa que la caridad, camino proclamado solemnemente tanto en el Antiguo como en el Nuevo Testamento.

Recordaremos aquí al lector ese problema cristiano, que tantos autores discuten, refiriéndose siempre a San Agustín. Se trata de la llamada "reducción" de todas las virtudes a la caridad. En el libro citado afirma San Agustín que la justicia es un amor justo, la fortaleza es un amor fuerte, la prudencia es un amor prudente y la templanza es un amor templado. $Y$ si las virtudes morales no son más que formas adjetivas de caridad, muchos "aristotélicos" se considerarán obligados a rechazar esa "reducción". Y en efecto, tienen razón, si hemos de distinguir las virtudes desde su "objeto formal": sería absurdo confundir la limosna con la castidad, con la sobriedad o con la generosidad. Pero la culpa no es de San Agustín, sino de esos mismos autores, que hablan de "reducción". No. San Agustín no redujo nada, no hizo mosto de toda clase de uvas. Lo que hizo fue otra cosa muy diferente. En lugar de colocarse en el "objeto formal" y dejando en paz a cada virtud con sus objetos formales (Objetivismo), prefirió situarse en el sujeto (Sujetivismo), en el mismo corazón del hombre: no busca, pues, el numerador, sino el común denominador. A Agustín no le interesa tanto el que yo dé limosna o guande virginidad: lo que me pregunta, es si eso lo hago por Dios, por vanidad, por orgullo, por egoísmo, por sordidez, para tapar vicios vergonzosos, para exhibir "brillańtes vicios". Lo que Agustín proclama, es el mismo sentido de la Biblia y concretamente del Cristianismo. Jerusalén no es Atenas, ni lo ha sido nunca. Está bien que los naturalistas se preocupen sobre todo de los objetos formales y del objetivismo: así progresará la ciencia y se afinará ese instrumento sutil y maravilloso, que es la Filosofía. Pero eso no es todo: no basta saber y más saber, en un orden especulativo. A ese "saber" hay que añadir el "amor" para que podamos decir que la Filosofía nos conduce $a$ un "Frui". En caso contrario, nos veremos obligados a decir que la Filosofía es una "asignatura", que se utiliza para esto o para lo otro, y que por ende sólo nos conduce 
a un "Uti". ¿Quién es entonces el que avasalla a la Filosofía, el cristiano o el racionalista, que no tiene salida posible? Luego entre ambos extremos vituperables, entre los que quieren convertir a la Filosofía en Ancilla Theologide y los que proclaman la fórmula "la Filosofía por la Filosofía", el camino de San Agustín es el humano, el práctico, el que no convierte al hombre en una serie de compartimentos estancos y de zonas técnicas, artificialmente unidas.

Pero no termina aquí la función de Cristo como "Camino". Porque cualquiera que lea el Evangelio se hallará sorprendido ante la novedad del mundo moral que aparece ante él, si trata de compararlo con la Etica a Nicómaco. Agustín sintetizó esa impresión de novedad, al presentarnos la "humildad-obediencia" de Cristo. Ese es el carácter del Verbo Encarnado, esa es la manera concreta de la Kenosis. No se trata aquí en realidad de "moralidad", sino de "metafísica" o, mejor dicho, la moralidad tiene unas bases metafísicas ${ }^{42}$. En el análisis del pecado aparece siempre la soberbia-rebelión como esencia del mismo pecado. La tendencia del hombre a ser sui juris le induce a todos los extremismos. Si Adán se apartó de Dios (y nos apartó a todos) por una soberbia-desobediencia, Cristo prefirió rescatarnos y domarnos suavemente con su humildad-obediencia. La humildad-obediencia tiene, pues, profundidad metafísica. Quisimos hacernos dioses y Dios se hizo hombre. Dios nos ofrecía en el Paraíso ser "dioses por gracia" y lo rehusamos: quisimos serlo por derecho propio, y lo perdimos todo. Vino Cristo, hecho carne, y nos ofreció una nueva posibilidad de ser "dioses por gracia". Tal es el fundamento de una espiritualidad cristiana ${ }^{43}$. Y de este modo volvemos al punto de partida, que Agustín presentaba en el De Moribus Ecclesiae. A la vista de Cristo, seguimos y conseguimos a Dios ${ }^{44}$.

Cristo es también el camino en cuanto que es el sentido de la Historia de la salvación. Así había visto a Cristo San Pablo. La Iglesia lo planteaba en la catequesis para el bautismo y Agustín nos ha contado la impresión que le produjo esta visión panorámica de la historia ${ }^{45}$, que respondía un poco al tema de los maniqueos: principio, medio y fin. Cualquiera que haya abierto $\mathrm{La}$ Ciudad de

42 Non quaesierunt Deum per humilitatis januam, quam in seipso Dominus Jesus Christus ostendit (De Lib. Arb. III, 9, \& PL. 32, 1.285).

43 Si tamen obvius placet sibi (homo) ad perverse imitandum Deum... Et hoc est initium omnis peccati superbia... Ei se Dominus ad imitationem humilitatis praeberet (De Lib. Arb. II, 25, 76, PL. 32, 1.308).

44 De Util. Credendi 15, 33, PL. 42, 89; De Mor. Eccl. I, 6, 10, PL. 32, 1.315; I, 11, 18 PL. 32, 1.319.

45 Niec satiabar illis dilebus dulcedine mirlabili, considerame altitudlinem consilii tui super sailutem generis humani (Confess. IX, 6, 14, PL. 32, 769). Esta profundidad idel consejo divino es, por una parte, la relación providencial entre la fel y la inteligencia; por otira parte, la distinción providiencilal entre sentido literal y espiritual; finalmente, por otra parrte, el plan de salvación en la his-: toria. Cfr. De Catech. Rud. 3, 5 y' 6, 10, PL. 40, 313 y 317; De Vera Rel. 24,45, PL. 34, 141 . 
Dios entenderá el partido que Agustín supo sacar a este proceso evolutivo y progresivo, que a veces parece anunciar un hegelianismo espiritual: dos potencias, dos Ciudades que luchan entre sí, terminan por empujar a la humanidad hacia el monoteismo, hacia el Sinaí, hacia el Profetismo, hacia la Encarnación y, finalmente, hacia una Iglesia, que sólo puede avanzar hasta una escatología maravillosa, que hoy apenas podemos entrever. No es fácil que Agustín haya previsto estas consecuencias "polémicas", aunque Heráclito había proclamado a la guerra (Pólemos), madre del progreso. Pero no podrá negarse que en La Ciudad de Dios late una dialéctica, que algunos han querido llamar filosofía de la historia, siguiendo la inspiración hegeliana, pero que no es otra cosa que la dialéctica de Cristo. Cristo está ya en el principio de la historia y la historia no es otra cosa que una revelación de Cristo, y también de su Espíritu, latente en el Antiguo Testamento, pero patente en el Nuevo y siempre conocido en el mundo con el nombre de Pneuma. Agustín utiliza, pues, el helenismo para destruir de raíz el helenismo. Hace historia, porque los griegos no podían admitir en absoluto una historia sino sólo una filosofía de la historia. Si la Humanidad ha percibido el concepto de historia y ha desarrolla'do tantas teorías de la historia, se lo debe a Cristo, que ha sido el alma de la historia, tanto en el Antiguo (Mesías) como en el Nuevo Testamento.

Este concepto estricto de la historia puede llevar a algunas exageraciones, por lo menos aparentes. Así Harnack denunció a Agustín por haber exagerado el sentido histórico y detallista del pecado original, estableciendo una dependencia real del hombre frente al diablo, que implicaba una dependencia de Dios. Agustín establece que el diablo logró cautivar al hombre, con mala intención, pero en buena lid. Por consiguiente, ese hombre fue su cautivo según normas de justicia y equidad. De donde parece deducirse que Cristo tenía que encarnar, como sometido a un plan de reconquista y desquite. Cristo tenía que vencer al diablo en su propio terreno, con sus propias armas, para libertar al hombre de la esclavitud según esas normas de justicia y equidad. Sólo cuando el diablo mató a Cristo inocente, saltándose así las normas de la guerra, perdió el derecho legítimo que había adquirido en su guerra contra Dios ${ }^{46}$.

Cristo tiene también una nueva función reveladora, que constituirá la "justificación de la fe" de que antes hablamos. En efecto, Cristo hizo milagros, revelándose así en las maravillas de la Naturaleza y de la Historia, como Jahvé

46 Verbum Dei unicus Dei Filius, diabolum... homine indutus etiam homini subjugavit... superans eum lege justitiae... Quoniam jure aequissimo vindicabat... Ut in illo vivant, qui pro eis quod debebant exsolvit... (De Lib. Art. III, 10, 3i, PL. 32, 1.280). Como se ve en el texto, no ste trata de busicar en el catolicismo un suceidáneo del Principio dell Mal, de lois maniqueos. Agustín y muchos atros autoreis conceden a veceess excelsivia impontancia all diablo, por artificio litieramiol 0 porr rutina atávica, perro no se engañan sobre el poider condicionado del diabilo. 
se manifestaba en las maravillas de la creación y de la misma historia ${ }^{47}$. A esto había que añadir la propagación de la misma Iglesia. También para Agustín, como para San Lucas, la propagación de la Iglesia es un fenómeno tan fuera de las normas, tan contrario a toda suposición o esperanza, que no tiene explicación fuera de la teología. Se explica gracias a un Arché, que es el Espíritu Santo, el Espíritu de Cristo. Dejaremos aquí estos dos puntos que nos llevarían muy lejos.

Pero este tema de Cristo "Camino" cobra para Agustín un sentido más original, desde el momento en que se ve precisado a renunciar a la mística neoplatónica, y a reconocer que entre Dios y el alma (Deum et animam scire cupio) no hay camino directo o inmediato. El "Camino" une y separa al mismo tiempo dos puntos distantes ${ }^{48}$.

La Encarnación empieza a ser, no ya sólo una "medicina" sino todo un régimen curativo, que da carácter típico a las virtudes humanas. $\mathrm{Fe}$, esperanza, caridad, humildad, obediencia, todo cobra sentido cristiano. Las concupiscencias fundamentales, especialmente la soberbia ${ }^{49}$, se plantean de modo, que la Encarnación del Verbo vendrá a designarse como "puerta de la humildad" ${ }^{50}$. El Verbo, que era la comida propia de las criaturas racionales, ángeles y hombres, como ya vimos en el apartado Cristo Verdad, termina por hacerse "carne", comida propia de hombres, comida de "carnales", comida apropiada a las miserables circunstancias de este penal y cautiverio de la tierra. $\mathrm{Y}$ de este modo, el hombre tiene que llorar de alegría, si tiene realmente corazón. Porque ha vuelto a comer en el destierro el pan de los ángeles ${ }^{51}$. Ya no hay mística racionalista, sino media-

47 Cfrr. H. Crouzes, Origène et la Philosozhie, Aubier 1962, 167-177. De Utilitate Credendi, 16,34 , PL. 42,89 s'.

48 De Gen. c. Manich. II, 8, 10, PL. 34, 201. El homibre es arrojaido del Paraíso, que era el símbolo de lai bienaventuranza. En adelante vivirú en la miseria y idie esa "miseria" vendrá a sacarle Cristo: apparendo hominibus in homine, cum Verbum caro factum est... blandiens eorum infirmitati, qui cor mundum nondum habiebaint, unde vidleretur Vierbum in principio, Deus carpud Dieum. (De Gen. c. Manich. II, 24, 37, PL. 34, 215).

49 De Lib. Arb. II, 19, 53, PL. 32, 1.269.

50 De Lib. Arb. III, 9, 28, PL. 32, 1.285.

51 Ex quo factum est ut illud Dei Verbum, per quem facta sunt omnia, et quo fruitur omnis angelica beatitudo, usque ad miseriam nostram clementiam suam porrigeret, et Verbum caro flieret et habitaret in nobis. Sic enim posset painem Angelorum homo manducare, nondum Angelis aequatus, si panis ipse Angelorum hominibus dignaretur aequari... intrinsecus pascens per id quod Deus est, nos forinsecus admonens per id quod nos sumus, idoneos fiecit per fidem, quos per speicilemi pascat alequallitem... Peccati poena tienebatur ad hoc diminulionis redacta, ut per conjecturas rerum visibilium ad intelligemda invisibilia niterotur: cibus rationalis creaturae factus est visibilis... ut visibilia sectantes ad Se invisibilem revocaret. Sic eum anima, quem superbiens intus neliquerat, foris humilem invenit, imitatura ejus humilitatem visibilem, et ad altitudinem invisibilem reditura (De Lib. Arb. III, 10, 29, PL. 32, 1.285). En esite hermoso texte tenemosi ya la teoría compiletal. 
ción ${ }^{52}$. Agustín tendrá que retractarse de haber insinuado que había camino fuera de Cristo ${ }^{53}$.

Todavía no ha perdido Agustín su optimismo neoplatónico: en el fondo el pecado original fue un bien: el hombre es la gloria de la Naturaleza terrestre ${ }^{54}$. Ya nos parece inminente el oír gritar: ¡Oh, feliz culpa! El Verbo encarnado está en relación esencial con el pecado. Las discusiones sobre otras "hipótesis" (si Adán no hubiera pecado, si no hubiera existido, si hubiera vivido en otro planeta, si hubiera sido un marciano, etc.), no interesan a Agustín ${ }^{55}$. Cristo es el nuevo Adán, que inaugura una nueva humanidad, y el Cristianismo es una religión de redención ${ }^{56}$. El año 393 expuso Agustín a los Padres del I Concilio de Hipona el Símbolo, y en él declara su pensamiento, ya maduro, sobre Cristo, que es Liberator noster et rector noster, Filius Dei ${ }^{57}$. No vamos a desarrollar aquí la doctrina de la redención, ni consideraremos a Cristo Camino, en cuanto Médico y Medicina, en Cuanto Sacerdote y Sacrificio, etc. Eso sería demasiado y, además, está bien estudiado. Sólo deseamos que cuando se estudien esas funciones de Cristo, se relacionen con el concepto fundamental de "Camino".

De este modo Agustín ha condicionado totalmente a la Filosofía. Un filósofo que ignore o pretenda ignorar ese condicionamiento teológico, es ya un mal informado, un incapacitado. Un filósofo que sólo sea filósofo no es ya ningún filósofo, sino un simple profesional, un técnico ${ }^{58}$. El filósofo ya no puede ir a Dios directamente, y necesita también él la mediación de Cristo. Cristo nos ha obligado a ir despacio, a no tener prisa por ver a Dios, a calmar nuestros nervios. Nos ha internado en el Sanatorio, que es su Iglesia, nos ha trazado una via bumilitatis, que es un método, un régimen terapéutico, y nos alimenta con

52 De Gen. c. Manich. II, 20, 30, PL. 34, 211 s.; De Lib. Arb. III, 25, 76, PL. 32, 1.308 .

53 Item, quod dixi ad sapientiqe conjunetionem non una via perveniri (Solil. I, 13, 23, PL. 32, 881), non bene sonat: quasi alia via sit praeter Chrisism, qui dixit: Ego sum via (Retract. I, 4, 3, PL. 32, 590).

54 De peccato nostro... genus humanum factus est magnum decus ornamentumque terrarum. (De Vera Relig. 26, 48-51, PL. 34, 154). Según Ios platónicos las almas "cayeron" y essto fue un mal: por" esio fueron casstigaadais. Perro la caídia era en realidad un bien, pruess lass almast allegran y hermossean la Naturraleza.

55 De Lib. Arb. III, 19, 54, PL. 32, 1.297.

56 De util. cred. 15, 33, PL. 42, 89; C. Fortunatum manich. 9, PL. 42, 116. Reqonciliationem nostram dixit frieri cum Die'o perr Jesum Christum (C. Fortunatum manich. 17, PL. 42, 119). Animas nostras de eadem inimicitia liberarel... et ad meum regresum Salvatorem esse Christum emissum (C. Fortunatum manich. 17, PL. 42, 119).

57 Caput est Ecclesaiae, quod est Christus homine indutus, per quem vivendi exemplum nobis daretur, hoc est via' certa qua perveniremus ad Deum. Non enim redire potuimus nisi humilitate, qui superbia lapsi sumus... Exemplum vicue qua redeundum fuit, ipse Reparator inoster in se ipso demostrare dignatus est (De Fide et Symbolo 4, 6, PL. 40, 184; 2, 3, PL. 40, 183).

58 Garriebam quasi peritus, et nisi in Christo Salvatore nostro viam tuam quarerem, non peritus, sed periturus essem (Confess. VII, 21, 27, PL. 32, 747). 
"carne" o con "leche" 59. En uno de los textos más hermosos, que Agustín haya escrito en toda su vida, se lamenta de haberse hecho tantas ilusiones filosóficas, cuando en realidad no hay más que un camino, camino de un Nuevo Testamento o alianza con Dios, camino que es Cristo ${ }^{60}$.

Nuestra buena razón humana, la potencia o facultad más alta del hombre, nace enferma, apegada, envenenada, animada por una suerte de instinto o tirón del mal, con ojos sucios y mirada extraviada. El éxito en la ciencia vital, en la ciencia de la verdad, es un galardón, una gracia, más bien que una conquista. Por eso, la misma razón se nos aleja, se nos queda en un segundo plano. Entretanto alcanza el primer plano el "amor". Sólo el amor es de verdad edificante, sólo él es el camino de la verdad. Esta proposición no se ha de entender en el sentido falso en que la entiende un Max Scheler: cuando decimos que el amor está delante de la Verdad, es como cuando decimos que El Espíritu Santo está delante del Hijo: no se trata de dignidad ni de origen, sino sólo de dialéctica, de proceso.

De este modo, se nos complica el proceso mismo. Porque también el amor nace enfermo, miope, concupiscente, estimulado de sordas comezones, arrastrado interiormente a los caprichos broncos y aleatorios, temerario para romper las leyes, anteponer lo inferior a lo superior y lo peor a lo mejor, aún a sabiendas de que obra mal. Y mientras él se impone apasionada o violentamente a la razón, ésta cede con facilidad y condesciende en una empresa abominable. Agustín exhibió en sus Confesiones un corazón humano, como un "Ulises" del siglo Iv. Ese Agustín era ya un hombre de la calle, el primer hombre de la calle que apareció ante la Sociedad. Pero para Agustín 'ese libro era un argumento: Agustín es el géneto humano y no tiene otro camino que Cristo.

Nos detendremos aquí. La esfera del Espíritu Santo, el Amor, tiene sus propias leyes. El amor se adelanta, como los Apóstoles, a preparar el lugar al que Cristo tiene que venir, purifica los espíritus, limpia los oịos, endereza las miradas, alimenta la caridad, sosiega y supera la concupiscencia. Pero todo eso nos descubre que no todo está terminado. Cristo es el Camino y es la Verdad, pero es también la Vida. Y en el misterio de la Vida es donde mejor conoceremos a Cris-

59 Sanari credendo poteram, ut purgatior acies mentis meae diriseretur aliquo modo in veritatem tuam semper manentem (Confess. VI, 4, 6, PL. 32, 722). Port esio ya no trienen salidia loss platónicos, que ison los mejorres entre todos los filósofoss: o ingrresan en el Crristianilsmo, a caien en la iteurgia y en el esppirritismo (De Vera Relig. 4, 7, PL. 34, 126).

60 Quaerebam viam comparandi roboris quod esset idoneum ad fruendum Te; nec inveniebam, donec amplecterer mediatorem Dei et hominum, hominem Christumi Jesum, vocantem, et dicentem: Ego sum via, vieritas et vita, et cibum cui capiendol invalidus eram, miscentem carni; quoniam Verbum caro factum est, ut infantiae nostrae lactesceret sepientia tua, per quam creasti omnia. Non enim tienjebam Dotminum meum Jiesum, humitisi humibem; nec cujus rei magistra esșet ejus infirmitas noveram (Confess. VII, 18, 24, PI. 32, 745). 
to. El Verbo se hizo carne, porque nacemos muertos. Cuando la Iglesia quiere bautizarnos, empieza por exorcizarnos. Cristo anunció, pues, su mensaje, exigiendo un mínimum para comenzar: el agua y el Espíritu Santo.

\section{CRISto ES LA VIDA.}

Esta tesis era conocida de Agustín desde el momento de su conversión, pero de momento le preocupaban sobre todo los problemas de la Verdad y del Camino. Quería "entender" y sólo así se resignaba a "creer". Cristo nos da en el bautismo la vida, la gracia, la sangre sobrenatural que llevará a todas partes alimento y respiración. Pero las fórmulas agustinianas de la primera época son genéricas y vagas ${ }^{61}$. Ya advertimos antes que la misma redención era interpretada como una habilidad para engañar al diablo ${ }^{62}$. No faltan, sin embargo, las fórmulas claras para demostrar la ortodoxia de Agustín en su polémica antimaniquea, como se ve en el debate con Fortunato y en la Exposición del Símbolo. Sólo que tales fórmulas eran tradicionales ya.

Donde Agustín comienza a abrirse un camino original es en el estudio detenido, reflexivo, profundo, que dedica a San Pablo. Es manifiesto que nunca hubiera dedicado tanta atención ali tema de las dos leyes que llevamos los hombres y que nos destrozan, si el maniqueismo no le hubiera iniciado en ese mundo de desgarramiento y guerra civil, y no le hubiera obligado más tarde a arrancar de las manos de los maniqueos cualquier pretexto bíblico. Agustín no sabía, a pesar de todo, lo que le esperaba en su estudio de San Pablo. No sabía que ese estudio iba a convertirlo en un "Doctor de la Gracia", en un arquitecto del mundo sobrenatural, del Cuerpo Místico de Cristo. Muchos libros existen ya sobre este tema y por ello nuestro cometido se reducirá a plantear el problema en los dos momentos en que Agustín inició una postura original, y a sustanciar el sentido general de la actividad agustiniana en busca de ese mundo en el que Cristo es la Vida. Esos dos momentos son los Comentarios a las Epístolas a los Gálatas y a los Romanos, que culminan en el libro $A$ Simpliciano, y la aparición de Pelagio.

Al principio el Santo vacila, porque no ve con claridad en qué consiste la "imagen de Dios" 63. A veces cree que se perdió con el pecado original y que

61 Non sicut homo sponte cecidit, ita etiam sponte surgere potest; porrectam nobis desuper dexteram Dei, id est Dominum nostrum. Jesum Christum fide firma teneamus (De Lib. Arb. II, 20, 54, PL. 32. 1.270).

62 Justissime itaque dimitere cogitur (diabolus) credentes in Eum, quem injustissime occidit (De Lib. Arb. III, 10, 31, PL. 32, 1.280; III, 25,76, PL. 32, 1.308; De vera Relig. 24, 45, PL. 34, 141; De Gen. c. manich. II, 24, 37, PL. 34, 215 s.; De util. cred. 15, 33, PL. 42, 89).

63 De div. Quaest. q. 51, 1 is. PL. 40, 32; 4, PL. 40, 33 s. 
tiene que sernos devuelta por Cristo, y entonces es una imagen sobrenatural ${ }^{64}$ que Cristo nos devuelve en el bautismo ${ }^{65}$. Apoyándose en fuentes teológicas, probablemente en San Ambrosio, afirma claramente que la imagen se perdió del todo ${ }^{66}$. La imagen de Dios es entonces la gracia, la vida sobrenatural. También los maniqueos afirmaban que el hombre recibe la imagen de Dios, criando recibe la gnosis o iluminación ${ }^{67}$. Así, Agustín hubiera planteado los problemas de la vida sobrenatural a la manera de San Ireneo ${ }^{68}$.

Pero su teoría del Verbo-Verdad y del Verbo-Camino le hacen ver que el hombre no se puede separar del Verbo: la naturaleza humana está esencial, indisolublemente unida al Verbo. Ser racional significa vivir iluminado ${ }^{69}$. Cuando la gracia divina entra en un alma, no tiene que conquistar nada, ni invadir un terreno extraño, sino que vuelve a entrar en su propia casa: es una reconquista. El significado de la esclavitud es la libertad, como aparece en las pinturas de las Confesiones ${ }^{70}$. En esa galería literaria y espiritual de las Confesiones, que ningún gran pintor ha sabido interpretar, se van sucediendo los esguinces de los esclavos y de las esclavas, como si fuesen coros de profetas del Antiguo Testamento. Todos llaman al Libertador, todos piden a las nubes y a la tierra que produzcan al Justo. Y cuando llega ese momento que llamamos conversión, no desfilarán ante nosotros los titanes y los héroes, sino que veremos a la sencilla oveja extraviada volver al redil siguiendo un lejano silbido del Pastor. La "imagen", que era imagen del Verbo, y en la cual resonaba la voz del Verbo, era como el norte y el eros, que no dejaba descansar a Agustín hasta que le llevó al arrepentimiento y a la conversión ${ }^{71}$. Durante esa conversión el Verbo empuja a Agustín, le

64 Ibid. broisio.

65 Ibid. Agustín tiene a la vistla una fuentie teológrica, quizá a San Am-

66 Signaculo imaginis propter peccatum amisso, remansit tantummodo creaturam (De div. Quaest. q. 67, PL. 40,67 \$.). Perrol, si se pierdió, ¿cómo pruede serr reistauirada? Por" esso, Aguistín ise retractia. (Retract. I, 26, PL. 32, 628). Distin-

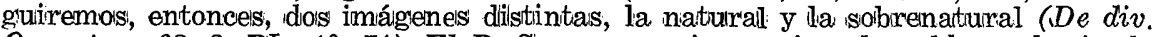
Quaest. q. 68, 2, PL. 40, 71). El P. Siommeris quiso zanjari el proibliema, haciendo cambiar de opinión a Agtulstín en ell año 412. Eiso es imporible, ya que continúa insistiendol en que la imagen se perdlió: quo vitio lex Dei deleta est de cordibus (De spiritu et litt. 27, 47, PL. 44, 229). Pero no ise perrdió del todio: non omni modo deletum est quod ibi per imaginem Dei, cum' crearetur, impressum est' (Ibid. 28, 48, PL. 44, 230). Se conservairon laist "rrelihguilas" de la imiagen (Ibid. 28, 49, PL. 44, 231). Esta firase imprressionaiba, con razón, a los reformadoreis diel s. XVI. 67 C. Faustum, 24, 1, PL. 42, 473.

68 Por esso, insiste Aguistín en la neciesidad de atienerise a los datos del Génesiis (C. Faustum, 24, 2, PL. 42, 475 s.).

69 Nisi supernae justitiae quaedam impressa vestigia teneremus... nisi aspergeretiur idesuper" velut tenuissima quaidlam aura justitiae, citius arescleremur quam sitiremus... Haec imago, vel vestigium de fastigio summo aequitatis impressum est. Sunt igitur omnes homineis una massia plecoati (Ad Simplichiamum, I, 2, 16, PL. 40, 120 s.).

70 Confess. IX, 1, 1, PL. 32, 763. PL. 32, 808 .

Ibíd. X, 24, 35, PL. 32, 794;

; X, 40, 65, PL. 32, 806 s.; X, 43, 70, 
infunde la vida, restaura la imagen ${ }^{72}$. Por lo tanto Agustín presenta las Confesiones como un documento fehaciente de que Cristo es la Vida.

Una vez que Agustín distingue con claridad dos imágenes de Dios en el hombre, la natural y la sobrenatural, comienza a expresarse con habilidad en un terreno difícil, que hasta cierto punto parece nuevo y que hoy llamamos "sobrenatural" 73. Cristo fue la Verdad' y el Camino. El habrá de ser también la Vida. Si fuimos creados en El y por El, también fuimos creados para El. La primera vez que Agustín contempló el panorama sobrenatural en su conjunto fue en el libro $A$ Simpliciano, ante una pregunta de San Pablo, que obliga a dar respuesta: "¿Qué tienes, que no hayas recibido?". Agustín pasó revista a los bienes y se llenó de amor y de pavor. La gracia divina, la gracia sobrenatural, que ahora surge como actividad propia de Cristo, va cobrando caracteres firmes, rasgos claros, se va definiendo poco a poco. Las "notas" de la gracia tendríamos que expresarlas en estos o parecidos términos:

1. Es "gratuita", como lo expresa la misma etimología.

2. Es "existencial", en cuanto se opone a esa energía salvaje que nos empuja al mal y que San Pablo llama "pecado". Es, pues, un arché o Principio que empuja hacia el bien ${ }^{74}$.

3. Es "libertadora", puesto que nos saca de una esclavitud ${ }^{75}$.

4. Es "totalitaria", dialéctica, imperial. No transige con distinciones y reservas hábiles, ni siquiera con un "initium fidei" ${ }^{76}$.

5. Es "eficaz". Puesto que Dios quiere que todos se salven, y no todos se salvan, tiene que haber gracia eficaz y gracia no eficaz ${ }^{77}$. De este modo, Dios predestina al bien, pero no al mal ${ }^{78}$.

72 Hoa enim agit spiritus gratiaje, ut imaginem Dei, in qua naturaliter facti sumus, instauret in nobis. Vitium quippe contra naturam est, quod utique sanat gratia (De spiritu et litt. 27, 47, PL. 44, 229).

73. El pecadior es responsable porquel continúa unido al Verbo, porque el Veribo le sigue illuminando y haciendo inexcusable mediante la imagen natural, que es "reliquia" die la imaggen sobrematural ( $D$ e spiritu et litt. 27, 48, PL. 44, 229 s.). Tlluminación del Verbo e imagen se ildentrifican de eise modo sencillo (Ibid. $28,48, \mathrm{PL} .44,230$ ). Por elso la función dell Verbo en cuanto Vida sigue de un modio connatural a la función diel Verbo en cuanto Vierdad, aunque sean de oriden diferentel (I bid. 28, 49, PIL. 44, 231).

74 Ad Simplicianum, 1, 2, PL. 40, 103. La gracia sé opone, pues, a la natunalleza, no la la Ley. Mordifica ai la Naturaileza, no a la comisciencia. Es ontológiciea, metrafíisica, no morral o noéltiical (Ibid. nn. 3, 6 y 7, PL. 40, 105).

75 Ibid. nn. 9, 10, 11, 12, 13 y 17 PL. 40, 106, 107, 110.

76 Velle (Ibíd. n. 11, PL. 40, 107). Initium fidei (Ibíd. q. II, 2, PL. 40, 111).

77 Ibid. n. 14, PL. 40, 119.

78 Ibid. nn. 15 y 16, PL. 40, 120. La fórmula "venció la grracia" significa que Agtusitín ise constidieraba a sí misismo como diefensor de la libertaid humana contria los maniqueos. Por eso, essta nueva visión o revelación de la grmacia le ameidirentó. Resisitió, pero fiue venicido, anteis des vencier él a Peliagio. Vío que si el hombre se entrega a la dialéctica de la g'racia recae en la antigua fé de Jahvé. Para Agustín la gracia dia o devuelve una libertad, que el pecador no tiene en su esclavitud al pecado. 
6. Es "misteriosa". La dialéctica humana no vale para imponer leyes a la misericordia de Dios. Agustín exclama, vencido: "triunfó la gracia". Esta primera exploración del terreno de la gracia divina no podía dejar de causar sorpresas entre los lectores de Agustín. El mundo no estaba acostumbrado a un lenguaje bíblico, sino más bien a un lenguaje griego. La historia de Abrahán, Isaac y Jacob, la historia del Paraíso y la de la Tierra de Promisión eran interpretadas según el estilo y el espíritu occidentales. $Y$ ahora de pronto, las frases de Agustín, acuñadas sobre las fórmulas de los Profetas que estudiaban la Alianza, causaban sorpresas. De ahí nació Pelagio, de la sorpresa que le produjeron estos desahogos de Agustín. Cuando un día reflexionó Pelagio sobre el sentido de una de esas fórmulas "dame lo que me mandas y mándame lo que quieres", sintió en su corazón una voz interior que le llamaba al combate. $Y$ en aquel momento se rebeló: Cristo es la Verdad, Cristo es el Camino, ya está bien; pero no es la Vida.

Pelagio se acoge a una fórmula de Salustio ${ }^{79}$ sin advertir el abismo que se abre entre un Naturalismo y un Creacianismo. Habla de una naturaleza pura de modo, que Cristo, a juicio de Agustín, sería una añadidura molesta a la Naturaleza ${ }^{80}$. Para marcar mejor su oposición, a la fórmula pelagiana "todo es naturaleza", opone Agustín la suya propia: "todo es gracia".81. Pero luego advierte que por los dos extremismos se llegaría al mismo resultado: si todo es naturaleza o si todo es gracia, no hay hecho diferencial. Agustín toma, pues, la precaución de ir apartando todo lo posible la naturaleza de la gracia ${ }^{82}$. La primera pertenece a una esfera que denominaremos "Esfera del Creador", mientras que la segunda será una "Esfera del Redentor". En esta esfera todos estamos muertos, mientras el Redentor no nos infunda la nueva vida. Por eso Cristo es la fuente de la gracia, la Vida.

Los dos rivales, después de las exploraciones preliminares, se concentran a la vista del pecado original, que se va a convertir en caballo de batalla, y desde

79 SALustro, Bellum Jugurt. Prólogo. La fórmula die Salusitio idice: faulso quaeritur de natura sua genus humanum. 'Cfx. De natura et gratia 2, 2, PL. 44, 248 s.; 6, 6, PL. 44, 250.

80 Ibid., 11, 12, PL. 44, 253; 19, 21, PL. 44, 256. Non ergo sic debemus laudare Creatorem ot cogamur, imo vero clonvincamar dicere supierfluum Salvatorem (Ibid. 34, 39, PL. 44, 266).

81 Ep. 177, 7, PL. 33, 768. Pelagiio quilere ser filósofo, naturalisista, a estilo gyriego: quemadmodum pihilosophi hujus mundi ( $E^{n}, 186,11,37$, PL. 33, 830). Si se trataise ide una natura pura en aibistracto, Agiustín se había diefinido ya, contria los maniqueos, con lla fórmula omnis natura, bona. Cftr. Ep. 186, nn. 21, 22 y 26, PL. 33, 824 y 825. Pero Pelagio quiere pasar a la teisis y lal hombrel concreto. e histórico y esso es una fallacia. Ademáis, isuppuesstio ell hecho histórico die la Encarnación, Aguistín ya no pruedie convenir con Pelagtio tampoco en la interpretación histónicla. Cifr. Ep. 187, 2, 4, PL. 33, 833 s.

82 De natura et gratia, 24, 26, PL. 44, 260: conditio naturae se opone a potestas misericordiae. 
él lanzan al medio el problema paulino: ¿Es justo Dios, o no es justo Dios? $\mathrm{He}$ aquí a las criaturas juzgando a su Creador. Los dos rivales se constituyen en defensores de la justicia divina. A juicio de Pelagio, acusa a Dios de "injusto" todo aquel que afirme que Dios nos envía al mundo heridos, contagiados, sin libertâd y sin fuerzas ${ }^{83}$; eso es, a su juicio, maniqueismo, blasfemia. Agustín protesta, pero a su vez presenta la denuncia: Es todavía más injusto todo aquel que afirme que nacemos inocentes, puros y buenos, pero condenados a esta penitenciaría, contra la cual se sublevan los hombres sin cesar porque no admiten que sea un penal. $Y$ no se trata tan sólo de los males externos, de los cuales quieren los hombres culpar a Dios. Se trata principalmente de los males internos. Pelagio trata de ser ciego para el mal como Aristóteles: de ese modo puede pensar que la Humanidad es una bandada de águilas ordenadas, que miran al sol de hito en hito. Agustín, que ha sentido en su propia carne la garra sucia del mal, piensa que la Humanidad es un "rebaño de tortugas" ${ }^{4}$. Es verdad que de cuando en cuando nace un águila, pero, aún entonces, si el águila quiere volar y mirar al sol, tendrá muchas lágrimas que derramar y quizá sangre.

Las posturas de ambos rivales eran la consecuencia de cuatro siglos de lucha del Clasicismo con el Cristianismo. Pelagio era el canto del cisne del Clasicismo antiguo. Pero iba a ser, al mismo tiempo, la semilla de cizaña lanzada al campo de la Iglesia para el futuro, una semilla de incesantes y siempre renovados humanismos. No sólo habría que rehacer todos los problemas filosóficos y teológicos, sino que habría que hacerse cargo de otros nuevos. Hoy el hombre contemporáneo se da cuenta de los problemas nuevos que iban brotando bajo la pluma de Agustín: libertad, pecado, concupiscencia, ignorancia, amor, imagen de Dios, naturaleza, gracia, Dios, mundo, hombre, bien, verdad, realidad, belleza, historia, sociedad, etc. Los dos campeones hablaron con sobrada claridad y dejaron al hombre el derecho de elegir una postura fundamental.

En cuanto a Agustín, no puede ser más claro el sentido de su polémica: Cristo es la Vida. Quizá hayamos pecado restringiendo el imperio de Cristo a unos límites excesivamnete estrechos, rigurosos y formales, pero fuera de Cristo no hay posibilidad alguna de vivir la vida sobrehumana. Quien no esté "en" Cristo es una rama seca, un sarmiento podado de la vid. Son del todo diferentes la gracia qua creati sumus y la gracia qua christiani sumus ${ }^{85}$. Para referirnos a ésta, que es la vida sobrenatural, hay que pasar por Cristo y por su Redención ${ }^{86}$.

Sustanciando el pleito, los dos rivales llegaron a colocarse, como aquellas madres del Juicio de Salomón, ante un recién nacido para disputárselo. Pelagio afir-

83 Opus. imp. c. Julianum, IV, 56, PL. 45, 1.372; IV, 89, PL. 45, 1.390; De Nuptiis et concup. II, 3, 8 s. PL. 44,440 s.

84 Opus imp. c. Julianum, V, 13, PL. 45, 1.442-3; V, 1, PL. 45, 1.431-3. 85 Ep. 177, 7, PL. 33, 768 .

86 Ibíd. 
ma que el niño es suyo: es una naturaleza pura, y por sí mismo alcanzará el Reino de los Cielos; únicamente, ya que tanto vienen presionando las objecciones bíblicas, esas moscas que Agustín levanta en todas partes, el niño no entrará en la Vida Eterna, si no le brindan el agua y el Espíritu Santo. Agustín se burla de tales distinciones y se congratula que haya comenzado el momento de la retirada estratégica de Pelagio: el niño no entrará ni en la Vida Eterna ni en ningún Reino de los Cielos: es una natura lapsa, que se ha caído de Cristo; si la Iglesia se apresta a bautizarlo, comenzará por unos elocuentes exorcismos ${ }^{87}$. En tiempo de Agustín no se hablaba todavía del "limbo", que es una palabra curiosa, para una realidad curiosa.

De esta manera llegó Agustín al final del drama evolutivo. Seguramente, cuando el anciano miraba hacia atrás, hacia la muchedumbre de sus obras, habría de sentir escalofríos. ¿Quién le había guiado por aquella selva doctrinal, que él no pudo ni siquiera soñar en los días de su conversión a Cristo? ¿Quién, sino el mismo Cristo, por quien había combatido? El anciano podía ver que el sistema se había cerrado y quedaba asegurado con muralla de acero. El hombre fue creado en el Paraíso, en la bienandanza, pero no quiso deberle a Dios esa gracia. Quiso independizarse y vivir por su propia cuenta, ser sui juris, y se cayó de Cristo, que es el Camino, la Verdad y la Vida. Pero Cristo no abandonó a su oveja perdida. Continuó siendo el Camino, la Verdad y la Vida para todos aquellos que de cualquier modo pudieran volver a "incorporarse a El". No hay para el hombre otra salvación que recogerse en un Cristo Místico. Eso es la Iglesia.

Terminaremos, pues, nuestro estudio constatando que Agustín renunció a la mística neoplatónica para elaborar otra mística más profunda y real. La unión directa e inmediata del hombre con Dios no se verifica ya en las potencias humanas, en la memoria, entendimiento y voluntad, de que nos hablan Aristóteles y Descartes, esto es, en unas potencias conscientes, mediante la ciencia, la visión, el amor, el fervor, los éxtasis, los deliquios y formas de desmayo. Ahora la unión se verifica en la "sustancia del alma", es unión sustancial. Ya no sólo somos cristianos, sino que somos Cristo, según la atrevida frase de Agustín. Es verdad que no somos dioses, no entramos en la Unión Hipostática, como la naturaleza humana y singular de Cristo. Pero tampoco somos expósitos admitidos en una casa ajena, hermanos "jurídicos" de Cristo. La Iglesia, abrumada por esta realidad misteriosa, inventó una fórmula que ha sido calificada de bárbara (ex opere operato), para designar esa unión ontológica e inconsciente, que llamamos justificación, filiación divina, vida sobrenatural. La sangre de Cristo, trasformada en gracia, es un torrente circulatorio de un Cuerpo Místico. No nos meten en casa aje-

87 De natura et gratia, 8, 9, PL. 44, 251. 
na, sino que volvemos a la nuestra, hermanos carnales, hermanos en la sangre, que son recobrados, recogidos, reincorporados, reabsorbidos. El Cristianismo es una Mística. Cristo es la Verdad, el Camino y la Vida.

Si volvemos ahora la mirada al principio de este estudio, hallaremos un camino largo y tortuoso, lleno de descubrimientos y sobresaltos, recorrido por un Agustín que no mira hacia atrás sino que corre ambicionando siempre metas nuevas y más elevadas. Comprenderemos al instante que haya tanta variedad de apreciaciones entre los críticos y exégetas de San Agustín ${ }^{88}$ y que todos tengan su parte de razón, según enfoquen el problema y según utilicen unos y otros textos. Es claro, sin embargo, que desde una unión accidental y cognoscitiva hemos pasado a una unión sustancial e inconsciente. Pero a lo largo de esa evolución, no sólo nos ha seguido Cristo, sino que ha sido $\mathrm{El}$ el hilo conductor y la razón de nuestro proceso ideológico. Y la consecuencia es que también hoy tendremos que renunciar a muchos "irenismos" que nos tientan, y tendremos que adquirir una consciencia clara de que quien extiende y propaga el Cristianismo, quien afianza la fe y enciende los corazones es un arché teológico, que llamamos "Espíritu de Cristo", Espíritu Santo. Nuestra misión será, pues, exactamente la misma que la de los primeros cristianos.

Ahora bien si nuestro Modelo y Camino ha de ser Cristo, no deberemos olvidar la suprema lección de la Unión Hipostática: "ni confusión, ni separación". No confundamos pues lo natural con lo sobrenatural, pero no lo separemos tampoco. ¿Qué puede significar entre cristianos una querella de los que tratan de confundir con los que tratan de separar? Significa que los unos y los otros tienen que buscar el buen Camino, que es Cristo, y entonces Cristo será también la Verdad y la Vida de su Cuerpo Místico, extendido por todo el mundo, encendido en el amor e iluminado por la verdad, llegado a la plenitud, convertido realmente en pléroma terrestre de Cristo.

\section{P. lope Cilleruelo, O. S. A.}

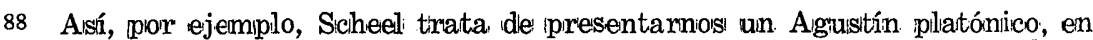
opossición al Cristianismo, ssin enterarmse ide que Agustín ha cambilado el platio nismo (O. ScHEeL, Die Anschauung Augustins über Chrisiti Person und Werk, Tübbingen-Leipzig, 1901). En sentidọ contratrio, Bavel suáriza, quiizá demasiado, los textos de Aguistín, y assí se piérde el isientidio de la evolución del Santo' (T-J. VAN Bavei, Relcherches sur la Christologie die St. Auoustin, Fribourg 1954). También Crombrugghte orienta su estuldio contra Sicheel. (C. vaN CrombrugGhe, "La Doctrine Sotériologique de Sit. Augustin": Rervue d'histoire ecclésiastique, 5 (1904) 237-257; 477-504. En realidiad ningún crítico niegra la evolución del peenstamiento aguistiniano. Sólo cabe dilsimular" o exagremar puntios concrertos. Cfr. J. Riviere, Le dogme de la Rédemption chez St. Augustin, 3 ed., Paris 1933, 365373. 